\title{
DOS NUEVAS ESPECIES DE POTENTILLA (ROSACEAE) DEL CENTRO DE MÉXICO*
}

\author{
Jerzy Rzedowski y Graciela Calderón de Rzedowski \\ Instituto de Ecología, A.C., Centro Regional del Bajío, Apdo. postal 386 \\ 61600 Pátzcuaro, Michoacán, México
}

\section{RESUMEN}

Se describen como nuevas e ilustran Potentilla butandae y P. queretarensis. La primera se conoce de un área restringida del noreste del estado de Guanajuato y está relacionada con $P$. ranunculoides Humb. \& Bonpl. ex Nestler, $P$. rydbergiana Rose y $P$. subcoriacea Rydb. La segunda sólo se ha colectado una vez en el municipio de San Joaquín, en el estado de Querétaro y parece estar vinculada con P. goldmanii Painter.

Palabras clave: México, Potentilla, Rosaceae

\begin{abstract}
Potentilla butandae and P. queretarensis are described as new and illustrated. The first one is known from a restricted area of northeastern Guanajuato and is related to $P$. ranunculoides Humb. \& Bonpl. ex Nestler, P. rydbergiana Rose and $P$. subcoriacea Rydb. The second was collected only once in the municipality of San Joaquín of the state Querétaro and seems to be related to $P$. goldmanii Painter.
\end{abstract}

Key words: Mexico, Potentilla, Rosaceae

El estudio de los componentes de la familia Rosaceae que habitan en la región que cubre la "Flora del Bajío y de regiones adyacentes" ha permitido revelar la existencia de dos plantas pertenecientes a Potentilla, cuyas características discrepan

\footnotetext{
* Trabajo realizado con apoyo económico del Instituto de Ecología, A. C. (cuenta 902-07), del Consejo Nacional de Ciencia y Tecnología y de la Comisión Nacional para el Conocimiento y Uso de la Biodiversidad.
} 
de las correspondientes a las especies conocidas del mencionado género. En tal circunstancia se describen a continuación:

Potentilla butandae Rzed. \& Calderón sp. nov. (Fig. 1).

Herba perennis; radix lignosa incrassata; caules plures, prostrati vel leviter ascendentes, scapiformes, usque $10 \mathrm{~cm}$ longi, dense piloso-hirsuti pilis patentibus usque $1.5 \mathrm{~mm}$ longis; folia omnia basalia, digitata, 5-foliolata, foliolis oblanceolatis vel obovatis, $0.5-2 \mathrm{~cm}$ longis, grosse serratis; inflorescentia pluriflora usque $5 \mathrm{~cm}$ longa et lata; bracteolae ellipticae, 2-3 mm longae, calycis lobuli oblongo-ovati, ca. $4 \mathrm{~mm}$ longi; petala lutea, obcordata, $5-5.5 \mathrm{~mm}$ longa; stamina ca. 20; ovaria plerumque minus quam 10, styli filiformes, subterminales; achenia ellipsoidea, ca. $1.3 \mathrm{~mm}$ longa, levia vel rugulosa.

Planta herbácea perenne, con raíz leñosa engrosada, hasta de $1 \mathrm{~cm}$ de diámetro y $20 \mathrm{~cm}$ de largo, de la que parten a menudo varios gruesos cáudices, cada uno de los cuales da origen a dos o más tallos; éstos rastreros a levemente ascendentes, hasta de $10 \mathrm{~cm}$ de largo, aunque por lo general más cortos, escapiformes, desprovistos de hojas y sólo llevando brácteas, densamente pilosohirsutos con pelos mayormente extendidos hasta de $1.5 \mathrm{~mm}$ de largo; hojas todas basales, a menudo escasas en la época de la floración, estípulas lineares, adnatas a la base de los peciolos, la porción libre hasta de $6 \mathrm{~mm}$ de largo, peciolos hasta de $5 \mathrm{~cm}$ de largo, con pubescencia similar a la de los tallos, láminas foliares digitadas, 5-folioladas, foliolos oblanceolados a obovados, de 0.5 a $2 \mathrm{~cm}$ de largo, de 0.2 a $1 \mathrm{~cm}$ de ancho, los laterales paulatinamente más chicos, redondeados a truncados en el ápice, largamente cuneados en la base, toscamente serrados en el margen de la mitad superior, enteros en la inferior, de textura coriácea en la madurez, verdes oscuros y seríceos a glabrescentes en el haz, más pálidos y seríceohirsutos, principalmente a lo largo de las nervaduras del envés; inflorescencias en forma de panículas cimosas plurifloras, bracteadas, hasta de $5 \mathrm{~cm}$ de largo y de diámetro, sus ejes piloso-hirsutos o seríceos, pedicelos delgados, hasta de $1.5 \mathrm{~cm}$ de largo, a menudo arqueados o sinuados; flores pentámeras; hipantio anchamente ciatiforme, de ca. $2.5 \mathrm{~mm}$ de diámetro, bracteolas elípticas, de 2 a $3 \mathrm{~mm}$ de largo, romas a algo agudas en el ápice, lóbulos del cáliz oblongo-ovados, de ca. $4 \mathrm{~mm}$ de largo, puntiagudos, seríceo-hirsutos por fuera, pubérulos por dentro; pétalos amarillos, obcordados, de 5 a $5.5 \mathrm{~mm}$ de largo, con uña de ca. $1 \mathrm{~mm}$ de largo, glabros; estambres ca. 20, filamentos de ca. $2 \mathrm{~mm}$ de largo, anteras oblongas, de 0.5 a $0.7 \mathrm{~mm}$ de largo; receptáculo piloso, ovarios por lo general menos de 10, pero a veces hasta 18, estilos filiformes, de inserción subterminal, de ca. $2 \mathrm{~mm}$ de largo; aquenios elipsoides, de ca. $1.3 \mathrm{~mm}$ de largo, de color crema o verdosos, lisos a rugulosos. 
Rzedowski y Calderón de Rzedowski: Dos nuevas especies de Potentilla del centro de México

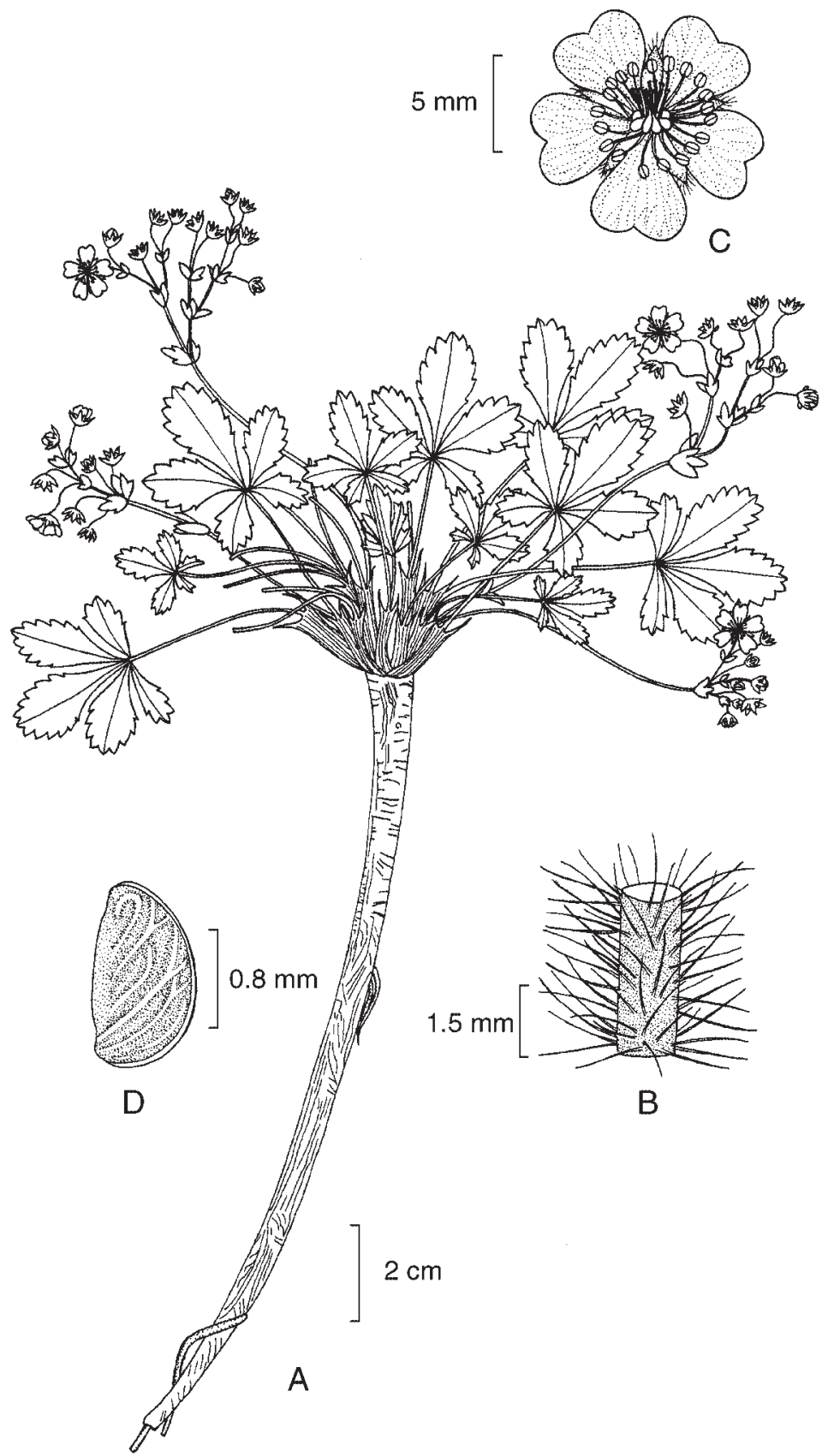

Fig. 1. Potentilla butandae Rzed. \& Calderón. A. aspecto general de la planta; B. trozo del tallo mostrando el tipo de pubescencia; C. flor vista de arriba, mostrando lóbulos del cáliz, pétalos, androceo y gineceo; D. aquenio. Ilustrado por Rogelio Cárdenas. 
TIPO: México, Guanajuato, Llanos de San Agustín, municipio de Victoria, alt. $2400 \mathrm{~m}$, pastizal en terrenos de poca inclinación, 2.VII.2005, J. Rzedowski 54160 (IEB), isotipos por distribuirse.

Material adicional examinado: México, Guanajuato, San Agustín, municipio de Victoria, S. Zamudio et al. 10777 (IEB); El Puerto Chiquito, municipio de Xichú, E. Ventura y E. López 7900 (IEB).

En virtud de reunir las siguientes características:

- planta perenne con raíz leñosa engrosada y cáudice bien desarrollado;

- hojas esencialmente basales, digitadas, con foliolos gruesos, dentados y verdes en ambas caras;

- pétalos amarillos, obcordados;

- estilos filiformes;

cabe ubicar a $P$. butandae en el grupo Subcoriaceae, de acuerdo con la definición de Rydberg (1908-1918, p. 320).

A su vez, la especie nueva difiere de los demás componentes conocidos del mencionado conjunto (P. ranunculoides Humb. \& Bonpl. ex Nestler, P. rydbergiana Rose y $P$. subcoriacea Rydb., todos distribuidos en el centro de México) en sus:

- tallos con pubescencia piloso-hirsuta con pelos extendidos;

- flores más pequeñas y mucho más numerosas;

- menor número de pistilos.

El nombre de la especie está dedicado como homenaje al Bibl. Armando Butanda, ameritado estudioso de la bibliografía y de la historia de la botánica de México.

Potentilla queretarensis Rzed. \& Calderón sp. nov. (Fig. 2).

Herba perennis; radix lignosa incrassata; caudex vix evolutus: caules plures erecti vel ascendentes usque $50 \mathrm{~cm}$ alti, villoso-sericei et breviter glandulosopuberuli; folia digitata, basalia 5-foliolata, foliolis cuneato-obovatis vel cuneatooblanceolatis, $1-3.5 \mathrm{~cm}$ longis, $0.4-2.5 \mathrm{~cm}$ latis, grosse serratis, membranaceis; inflorescentia pluriflora usque $25 \mathrm{~cm}$ longa, glanduloso-puberula; bracteolae oblongae vel ellipticae, 3-4 mm longae, calycis lobuli lanceolati vel ovati, 5-7 mm longi; petala lutea, obcordata, $8-10 \mathrm{~mm}$ longa; stamina ca. 20; ovaria minus quam 20, styli filiformes; achenia ellipsoidea, 1-1.5 mm longa.

Planta herbácea perenne, con raíz leñosa engrosada, pero sin formar cáudice conspicuo; tallos varios partiendo de la base, erectos o ascendentes, hasta de $50 \mathrm{~cm}$ 
Rzedowski y Calderón de Rzedowski: Dos nuevas especies de Potentilla del centro de México

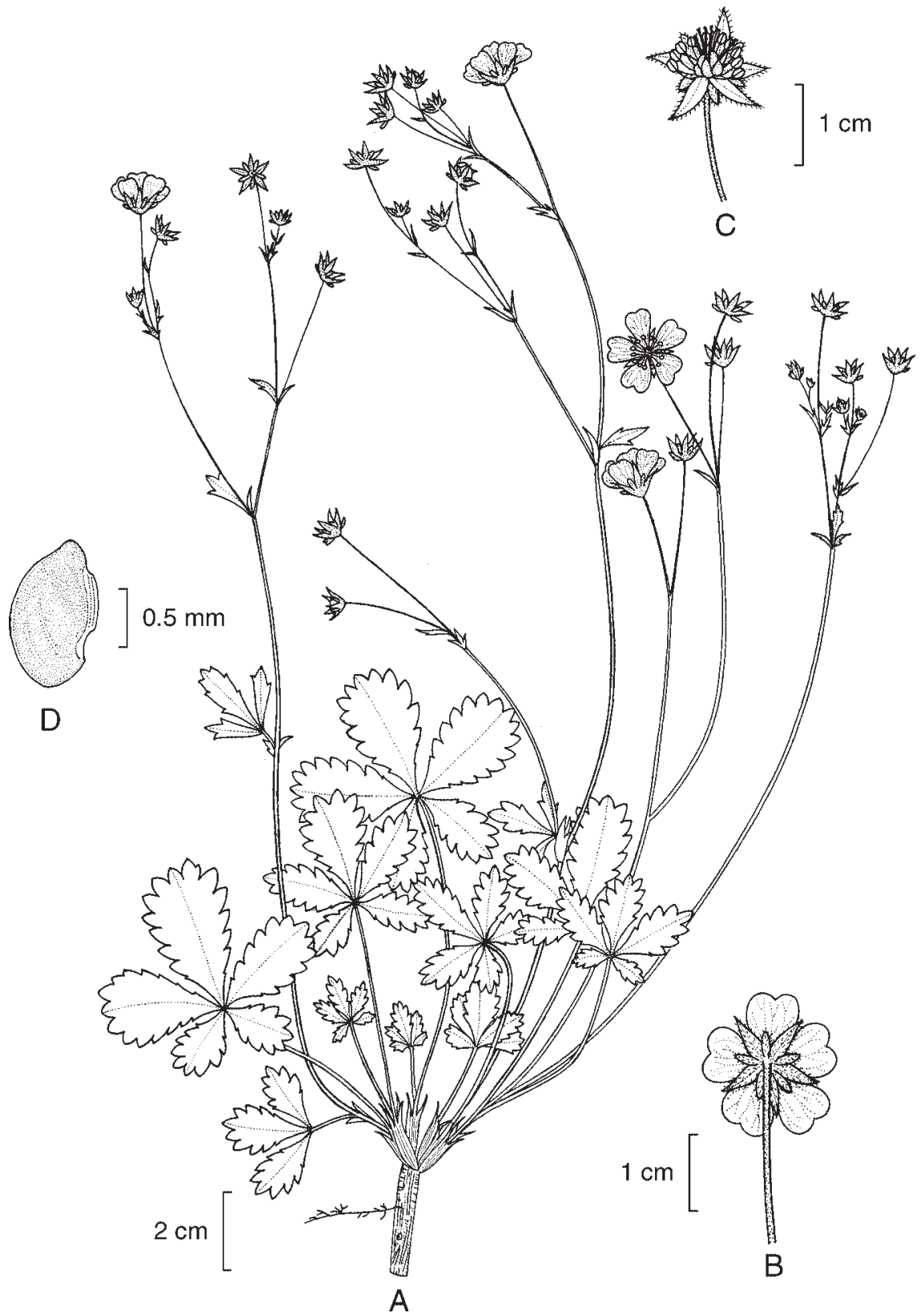

Fig. 2. Potentilla queretarensis Rzed. \& Calderón. A. aspecto general de la planta; B. flor vista por detrás, mostrando bracteolas, segmentos del cáliz y pétalos; C. flor desprovista de pétalos, mostrando bracteolas, segmentos del cáliz, androceo y gineceo; D. aquenio. Ilustrado por Rogelio Cárdenas. 
de alto, hasta de $3 \mathrm{~mm}$ de diámetro, sin ramificarse por debajo de la inflorescencia, viloso-seríceos con pelos mayormente aplicados hasta de $1.5 \mathrm{~mm}$ de largo y además con pelos glandulosos cortos mezclados de manera no muy uniforme; hojas digitadas, estípulas lanceoladas, hasta de $10 \mathrm{~mm}$ de largo, las de las hojas caulinas a menudo con dientes en el margen, persistentes, peciolos de las hojas basales hasta de $8 \mathrm{~cm}$ de largo, seríceos, sus foliolos 5, cuneado-obovados o cuneadooblanceolados, de 1 a $3.5 \mathrm{~cm}$ de largo, de 0.4 a $2.5 \mathrm{~cm}$ de ancho, los laterales paulatinamente más pequeños, ápice redondeado a truncado, base cuneada, toscamente serrados en el margen, de textura membranácea, seríceos en ambas superficies, pero con la pubescencia concentrada en las nervaduras del envés y además provistos de pelos glandulosos cortos, hojas caulinas mayormente trifolioladas, de tamaño más reducido y cortamente pecioladas a casi sésiles; inflorescencia en forma de panícula cimosa pluriflora, bracteada, hasta de $25 \mathrm{~cm}$ de largo y $10 \mathrm{~cm}$ de diámetro, sus ejes con pubescencia similar a la de los tallos, pero por lo común con mayor cantidad de pelos glandulares, pedicelos hasta de $5 \mathrm{~cm}$ de largo; hipantio pateliforme, bracteolas oblongas a elípticas, de $3 \mathrm{a} 4 \mathrm{~mm}$ de largo, por lo general algo agudas u obtusas en el ápice, algunas veces bífidas o con tendencia a bifurcarse, lóbulos del cáliz lanceolados a ovados, de $5 \mathrm{a} 7 \mathrm{~mm}$ de largo, agudos a acuminados en el ápice, hirsutos y glanduloso-pubescentes por fuera, casi glabros o escasamente pubescentes por dentro; pétalos amarillos, obcordados, de 8 a $10 \mathrm{~mm}$ de largo, con uña de ca. de $2 \mathrm{~mm}$ de largo, glabros; estambres ca. 20, filamentos de ca. $2 \mathrm{~mm}$ de largo, anteras oblongas o subcuadradas, de 0.6 a $0.8 \mathrm{~mm}$ de largo; receptáculo blanco-piloso, ovarios menos de 20, estilos filiformes, de ca. $2 \mathrm{~mm}$ de largo, de inserción subterminal; aquenios elipsoides, verdosos, de 1 a $1.5 \mathrm{~mm}$ de largo, lisos o rugulados.

TIPO: México, Querétaro, $3 \mathrm{~km}$ al $\mathrm{S}$ de San Joaquín, municipio de San Joaquín, 29.X.1985, bosque de encino, creciendo entre rocas, alt. $2400 \mathrm{~m}, R$. Fernández Nava 3237 (IEB, isotipo en ENCB).

P. queretarensis parece estar relacionada con P. goldmanii Painter, descrita de Oaxaca y citada también de Veracruz y de Guatemala, en función de las siguientes semejanzas:

- tamaño y porte de la planta;

- cáudice relativamente poco desarrollado;

- presencia de la pubescencia glandular;

- tamaño, forma y textura de las hojas;

- tamaño y forma de la inflorescencia;

- tamaño de las flores. 
Rzedowski y Calderón de Rzedowski: Dos nuevas especies de Potentilla del centro de México

Sin embargo, difiere de esta última en:

- falta de pubescencia extendida en los tallos;

- margen aserrado (no crenado) de los foliolos,

- lóbulos del cáliz conspicuamente más largos (no del mismo largo) que las bracteolas;

- número relativamente reducido de ovarios.

Aunque la especie nueva constituye el primer registro de Potentilla para el estado de Querétaro, aún cabe esperar el descubrimiento de la presencia de otros componentes del género en el territorio de esta entidad.

\section{LITERATURA CITADA}

Rydberg, P. A. Rosaceae. 1908-1918. In: North Amer. Fl. 22: 239-533.

Recibido en agosto de 2005. Aceptado en septiembre de 2005. 